\title{
Comparative effects of the herbicides dicamba, 2,4-D and paraquat on non-green potato tuber calli
}

\author{
Franciso P. Peixoto ${ }^{a}$,*, José Gomes-Laranjo ${ }^{a}$, \\ Joaquim A. Vicente ${ }^{b}$, Victor M.C. Madeira ${ }^{c}$
}

\author{
${ }^{a}$ Department of Chemistry, University of Trás-os-Montes and Alto Douro-CECAV, Apartado 1013, \\ 5000-911 Vila Real, Portugal \\ ${ }^{\mathrm{b}}$ Department of Botany, IMAR, Interdisciplinary Center of Coimbra, University of Coimbra, 3004-517 Coimbra, Portugal \\ 'Department of Biochemistry, University of Coimbra, 3004-517 Coimbra, Portugal
}

Received 21 July 2007; received in revised form 30 November 2007; accepted 9 December 2007

\section{KEYWORDS \\ 2, 4-D; \\ Dicamba; \\ Herbicide; \\ Oxidative stress; \\ Paraquat}

\begin{abstract}
Summary
The effects of the herbicides 1,1'-dimethyl-4,4'-bipyridylium dichloride (paraquat), 3,6-dichloro-2-metoxybenzoic acid (dicamba) and 2,4-dichlorophenoxyacetic acid $(2,4-D)$ on cell growth of non-green potato tuber calli are described. We attempted to relate the effects with toxicity, in particular the enzymes committed to the cellular antioxidant system. Cell cultures were exposed to the herbicides for a period of 4 weeks. Cellular integrity on the basis of fluorescein release was strongly affected by $2,4-\mathrm{D}$, followed by dicamba, and was not affected by paraquat. However, the three herbicides decreased the energy charge, with paraquat and 2,4-D being very efficient. Paraquat induced catalase (CAT) activity at low concentrations $(1 \mu \mathrm{M})$, whereas at higher concentrations, inhibition was observed. Dicamba and 2,4-D stimulated CAT as a function of concentration. Superoxide dismutase (SOD) activity was strongly stimulated by paraquat, whereas dicamba and 2,4-D were efficient only at higher concentrations. Glutathione reductase (GR) activity was induced by all the herbicides, suggesting that glutathione and glutathione-dependent enzymes are putatively involved in the detoxification of these herbicides. Paraquat slightly inhibited glutathione S-transferase (GST), whereas 2,4-D and dicamba promoted significant activation. These results indicate that the detoxifying mechanisms for 2,4-D and dicamba may be different from the mechanisms of paraquat detoxification. However, the main cause of cell death induced by paraquat and $2,4-\mathrm{D}$ is putatively related with the cell energy charge decrease.
\end{abstract}

(c) 2008 Elsevier $\mathrm{GmbH}$. All rights reserved.

*Corresponding author. Tel.: +351259 320273; fax: +351259320480.

E-mail address: fpeixoto@utad.pt (F.P. Peixoto). 
F.P. Peixoto et al.

\section{Introduction}

Large amounts of herbicides are released into the environment every year as a consequence of weed control in agriculture technologies. It is therefore important to know the biochemical cytotoxicity exerted by herbicides in metabolic activities. Three herbicides belonging to different representative chemical families were investigated in this study: $1,1^{\prime}$-dimethyl-4,4'-bipyridylium dichloride (paraquat), 2,4-dichlorophenoxyacetic acid (2,4-D) and 3,6-dichloro-2-metoxybenzoic acid (dicamba). A considerable amount of these compounds is absorbed via roots and aerial parts and retained by plants. Paraquat affects photosynthesis, being reduced by light reaction I (Cremlyn, 1991). Because it is absorbed from the foliage, but not from the roots, it was expected of to exert low toxicity on non-green cells.

Cell cultures of callus from potato roots (Solanum tuberosum L.) have been used as a model to evaluate the phytotoxicity and the metabolism of several herbicides (Sandermann et al., 1984). The absence of a complex structural organization and a more efficient exposition to environmental stress are advantages of this sensitive model for toxicity evaluation (Smeda and Weller, 1991).

Oxidative stress induced by several herbicides (Farrington et al., 1973; Lambert and Bondy, 1989; Nordquist et al., 1994) through active oxygen species may disrupt the membrane integrity as a consequence of lipid peroxidation. Further, DNA, proteins and pigments are also targets of the oxidation stress (Carbonera and Azzone, 1988; Davies et al., 1987; Mishra and Choudhuri, 1999; Pamplona et al., 1999; Scandalios, 1993). Aerobic organisms have developed complex protection systems against oxidative stress (Sies, 1993). Plants, as a consequence of photosynthesis, concentrate the highest level of cellular oxygen compared with other organisms. Therefore, plants are particularly challenged with oxidative stress and oxidation disturbance (Scandalios, 1993).

When the steady state of prooxidants and antioxidants is disrupted, a misbalance in favor of the prooxidants follows, which may severely affect metabolic activities, with eventual disruption of cellular homeostatic control, resulting in loss of cell viability.

Here, we compared the cytotoxic effects of the widely used herbicides paraquat, 2,4-D and dicamba on cell cultures of callus from potato roots (S. tuberosum L.), with respect to cell growth, total synthesized protein, cellular integrity, adenine nucleotides contents and several antioxidant enzymes.
Materials and methods

\section{Chemicals}

Sources of herbicides were as follows: paraquat (purity 98\%) was a gift of $\mathrm{ICI}$ Agrochemicals, UK; dicamba and 2,4-D were purchased from FLUKA. Adenosine nucleotides were obtained from Sigma (St Louis, Mo., USA). HPLC-grade methanol was from Merck. All other chemicals were of the highest purity commercially available.

\section{Plant materials}

Potato tuber calli were obtained from segments of adventitious roots developed from spouts of potato (S. tuberosum L.) tubers. The segments were excised and cultured on Murashige and Skoog solid medium supplemented with $2 \mathrm{mg} / \mathrm{L}$ 2,4-D. In about 4 weeks, callus tissue was obtained and kept under suitable experimental conditions by subculturing every 4-6 weeks (Montezuma-de-Carvalho and Guimarães, 1976). Callus tissue was grown on media with differing concentrations of different herbicides.

\section{Membrane integrity}

The amount of fluorescein released by cells into the culture medium was measured as an index of membrane integrity, according to the modified method of Persidsky and Baillie (1977). Cells (1 g) were inoculated for $72 \mathrm{~h}$ on Murashige and Skoog liquid medium supplemented with different concentrations of herbicides. Fluorescein release was estimated from the absorbance at $485 \mathrm{~nm}$. Full fluorescein release was established with heat-killed cells $\left(60^{\circ} \mathrm{C}, 10 \mathrm{~min}\right)$ and corresponds to an $A$ of $0.361 \pm 0.018$.

\section{Quantification of nucleotides}

Adenine and pyridine nucleotides were extracted using an acidic extraction procedure and were separated by reverse-phase liquid chromatography, as described previously by Stocchi et al. (1985). Briefly, acidic extraction was performed as follows: $1 \mathrm{~g}$ of cells was added to $1 \mathrm{~mL}$ ice-cold $0.6 \mathrm{M} \mathrm{HClO}_{4}$. After $5 \mathrm{~min}$, the mixture was vortexed, centrifuged for $2 \mathrm{~min}$ at $10,000 \mathrm{rpm}$ in an Eppendorf bench centrifuge at $0{ }^{\circ} \mathrm{C}$ and the pellet was discarded. The supernatant was neutralized with $3 \mathrm{M} \mathrm{KOH}$ and centrifuged again $(10,000 \mathrm{rpm}, 2 \mathrm{~min})$ in order to precipitate all the $\mathrm{KClO}_{4}$ produced. The supernatant fluid was filtered through Millipore filters $(0.22 \mu \mathrm{m}$ diameter $)$ and stored at $-80^{\circ} \mathrm{C}$ for further chromatographic analysis. All extraction procedures were carried out at $0-4{ }^{\circ} \mathrm{C}$ to minimize degradation of nucleotides. The chromatographic apparatus was a Beckman System-Gold, consisting of a binary pump and a 166 variable UV detector, controlled by a computer. The detection wavelength was $254 \mathrm{~nm}$ and the column used was a Lichrospher 100 RP-18 $(5 \mu \mathrm{m})$ from Merck (Darmstadt, Germany). During each run, an isocratic elution with $100 \mathrm{mM}$ potassium phosphate buffer $\mathrm{pH} 6.5$ and $1 \%$ 
methanol for $10 \mathrm{~min}$, followed by a $5 \mathrm{~min}$ linear gradient up to $10 \%$ methanol was performed with a flow rate of $1.25 \mathrm{~mL} / \mathrm{min}$. The time required for each analysis was $5 \mathrm{~min}$. The detection limit for each analyte ranged from 3 to 5 pmol.

\section{Enzyme assays}

Enzymes were assayed in crude extracts of callus tissue growth on different concentrations of herbicides. Callus tissue was ground in liquid nitrogen to a fine powder in a mortar and pestle. Proteins were extracted (at $0-4{ }^{\circ} \mathrm{C}$ ) by additional grinding with $5 \mathrm{~mL}$ of extraction buffer containing $50 \mathrm{mM}$ Tris- $\mathrm{HCl}(\mathrm{pH} 7.0), 20 \%$ glycerol, $1 \mathrm{mM}$ ascorbate, $1 \mathrm{mM}$ DTT, $1 \mathrm{mM} \mathrm{Na}$-EDTA, $1 \mathrm{mM} \mathrm{GSH}$ and $5 \mathrm{mM}$ $\mathrm{MgCl}_{2}$. For catalase (CAT), the medium was supplemented with $1 \%$ polyvinylpolypyrrolidone. The homogenate was centrifuged for $6 \mathrm{~min}$ at $12,000 \mathrm{~g}$. The supernatant was centrifuged for $20 \mathrm{~min}$ at $26,000 \mathrm{~g}$. The clear supernatant was used for assays of CAT, superoxide dismutase (SOD), glutathione reductase (GR) and glutathione $S$-transferase (GST).

CAT activity was determined by monitoring the disappearance of $\mathrm{H}_{2} \mathrm{O}_{2}$ according to the method of Beers and Sizer (1952). Total SOD activity was measured by determining the amount of enzyme required to produce $50 \%$ inhibition of the reduction of cyt $c$ by superoxide generated by xanthine oxidase, as described by Forman and Fridovich (1973). GR activity was determined by monitoring the glutathione-dependent oxidation of NADPH, as described by Schaedle (1977). GST activity was measured spectrophotometrically at $340 \mathrm{~nm}$ using 1 chloro-2,4-dinitrobenzene (CDNB) as substrate (Habig et al., 1974). Assays $(3 \mathrm{~mL})$ contained the following final concentration of reagents: $0.17 \mathrm{M} \mathrm{K}$-phosphate buffer $\mathrm{pH} 7.5,3.3 \mathrm{mM} \mathrm{GSH}$ and $1 \mathrm{mM}$ CDNB, and were incubated at $25^{\circ} \mathrm{C}$.

\section{Protein assays}

Proteins were measured by the method of Bradford (1976) with bovine serum albumin as standard.

\section{Results}

Among the herbicides studied (paraquat, 2,4-D and dicamba), paraquat exerted the highest cytotoxicity, followed by 2,4-D and dicamba (Figure 1). In the presence of $0.5 \mu \mathrm{M}$ herbicide, paraquat inhibited the cellular growth of non-green potato tuber callus by $20 \%$, in contrast with the other tested herbicides, which were not inhibitory at that concentration. Inhibition of cellular growth by about $20 \%$ was reached with $5 \mu \mathrm{M} 2,4-\mathrm{D}$ and $20 \mu \mathrm{M}$ dicamba. Total growth inhibition occurred at $50 \mu \mathrm{M}$ paraquat, $100 \mu \mathrm{M}$ 2,4-D and $250 \mu \mathrm{M}$ dicamba (Figure 1). This strong effect of paraquat is

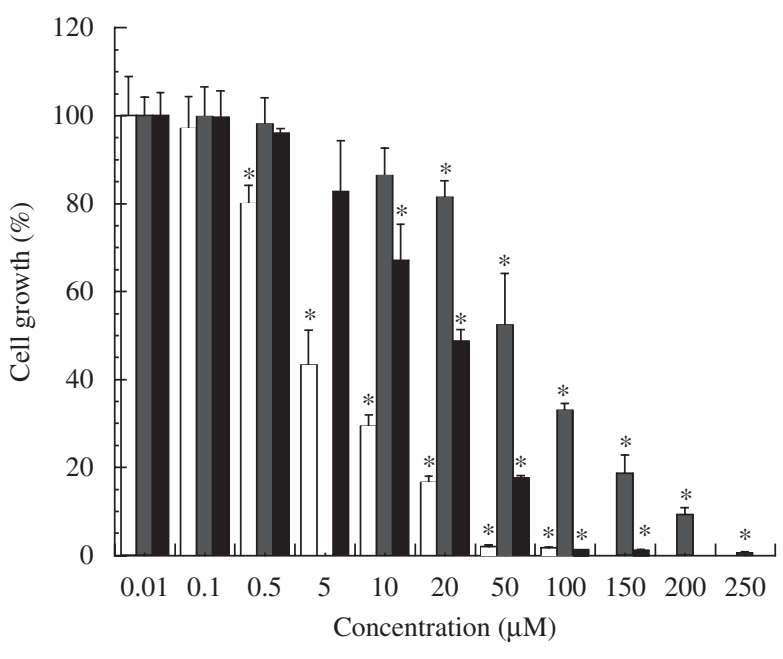

Figure 1. Concentration dependence of paraquat (white), dicamba (gray) and 2,4-D (black) inhibitory effects on the cell growth of non-green potato callus. Approximately $0.1 \mathrm{~g}$ cells were incubated for $30 \mathrm{~d}$ in a solid Murashige and Skoog medium, as described in the Methods section. ${ }^{*} P<0.05$, compared with the control. Data shown represent the mean \pm SD of 10 independent experiments.

surprising, as the photosynthetic apparatus is generally assumed to be the main toxicity target in plant cells (Cremlyn, 1991).

The herbicides 2,4-D and dicamba increased the protein/cellular weight ratio, in contrast with paraquat, which did not induce a significant alteration ratio (Figure 2 ). This is putatively related with the integrity of the cell membrane affected by 2,4-D and dicamba, but not paraquat.

The effect of the three herbicides on the integrity of the cellular membrane was examined through measurement of fluorescein release (Persidsky and Baillie, 1977). Concentrations inhibiting cell growth by $20 \%(0.5 \mu \mathrm{M}$ paraquat, $5 \mu \mathrm{M} 2,4-\mathrm{D}$ and $20 \mu \mathrm{M}$ dicamba) and 50\% (5 $\mu \mathrm{M}$ paraquat, $20 \mu \mathrm{M}$ 2,4-D and $50 \mu \mathrm{M}$ dicamba) were used. Full fluorescein release (100\%) was assigned to cells submitted to $60^{\circ} \mathrm{C}$ for $60 \mathrm{~min}$. For controls, herbicides alone were tested for spectroscopic interferences of fluorescein measurement at $458 \mathrm{~nm}$, and no effects were detected (data not shown).

Figure 3 illustrates our finding that 2,4-D induced the highest fluorescein release, followed by dicamba. Paraquat, at the concentrations used, induced no significant fluorescein release. Concentrations of paraquat, which significantly affect cell growth in a sustained exposure for $30 \mathrm{~d}$, induced no immediate effects on cells. This likely relates to the insensitivity of cell membrane integrity to paraquat, in contrast with 2,4-D and dicamba. Paraquat studies on potato tuber mitochondrial 


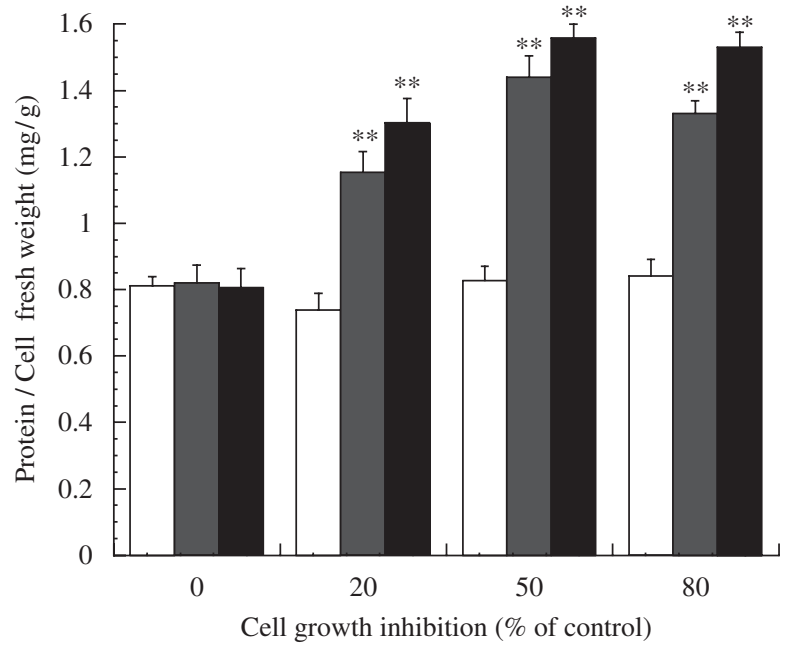

Figure 2. Effects of paraquat (white), 2,4-D (black) and dicamba (gray) on the relationship between total protein and cell growth of non-green potato callus. Asterisks indicate a significant difference (Student's $t$-test, $P<0.001$ ) relative to the control (herbicide absence). Vertical bars indicate the standard error of the mean (SEM) for seven independent experiments. ${ }^{* *} P<0.01$; ${ }^{*} P<0.05$, compared with the control.

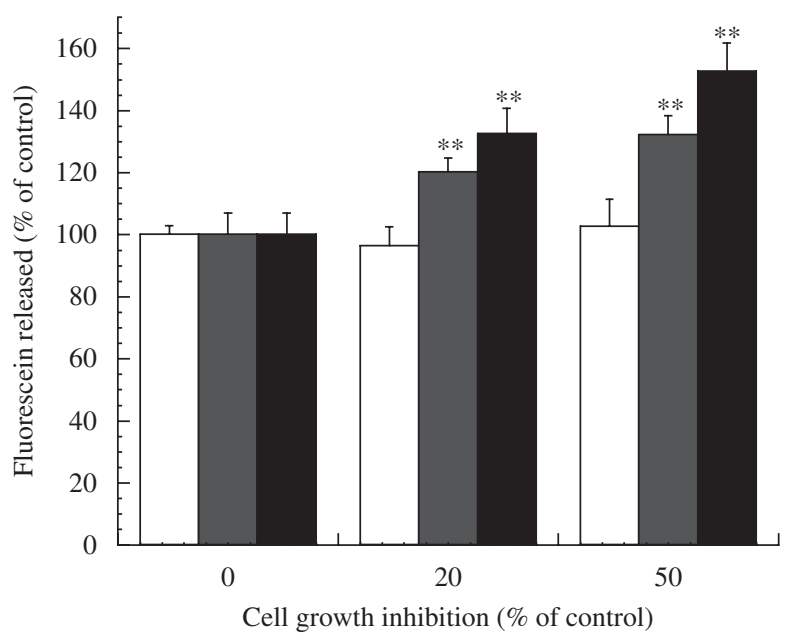

Figure 3. Cell membrane disruption (fluorescein release) promoted by paraquat (white), 2,4-D (black) and dicamba (gray). Vertical bars indicate the standard error of the mean (SEM) for seven independent experiments. ${ }^{* *} P<0.01 ;{ }^{*} P<0.05$, compared with the control.

fractions (Vicente et al., 2001) previously showed no sensitivity of swelling dependent on permeabilization to $\mathrm{H}^{+}$(even with $30 \mathrm{mM}$ paraquat), in contrast with $\mathrm{H}^{+}$permeabilization induced by 2,4-D and dicamba (Peixoto et al., 2004). These results indicate the capability of 2,4-D and dicamba to disrupt the membrane integrity, probably as a consequence of perturbation of membrane structure upon partition of the herbicides. In contrast, paraquat is not soluble on the cell membrane. This explains its lack of effect on fluorescein release even at concentrations inhibiting cellular growth by $50 \%$.

The decrease in the intracellular content of adenosine nucleotides is an indicator of inhibitory effects on the energetic metabolic pathways (Palmeira et al., 1994a). The results on adenosine nucleotide content yield information regarding the action of these herbicides on oxidative phosphorylation, glycolysis and pentose pathways.

Exposure of callus tissue cultures to 2,4-D, dicamba and paraquat results in a decrease of intracellular ATP content. The decrease in ATP was reflected by a simultaneous increase in intracellular ADP and AMP. Paraquat induced ATP and ADP depletion more effectively together with an increase of AMP. Further, dicamba was the least efficient of the three herbicides (data not shown). The energy charge alteration informs our understanding of the effect of herbicides on adenosine nucleotides as a whole (Figure 4). Paraquat and 2,4-D (up to 20 and $50 \mu \mathrm{M}$ ) were very efficient in decreasing the cell energy charge. Conversely, even at $200 \mu \mathrm{M}$, dicamba decreased the energy charge only by a maximum of about $26 \%$.

The $N A D^{+} / \mathrm{NADH}$ ratio increased as a measure of cellular redox state decrease, reflecting degradative

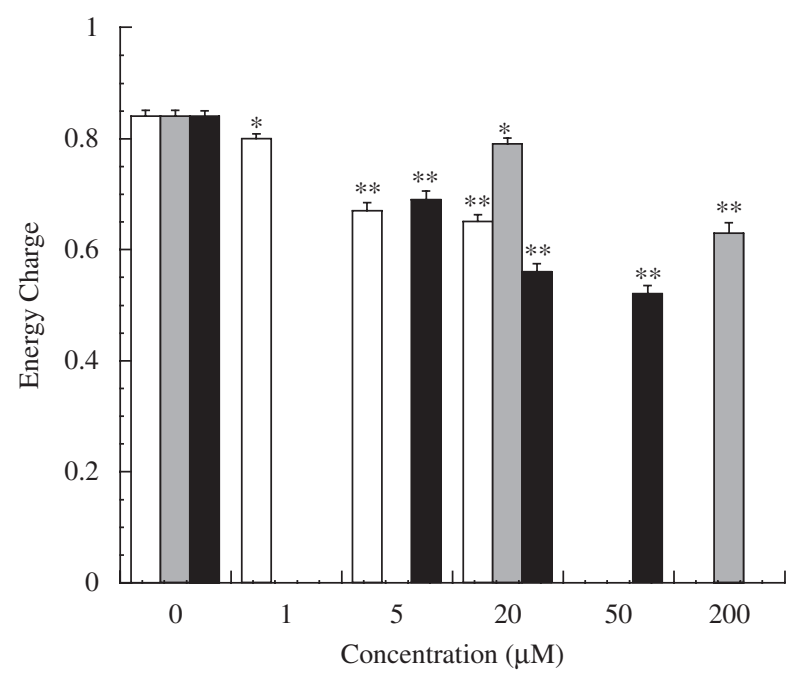

Figure 4. Effects of paraquat (white), 2,4-D (black) and dicamba (gray) on energy charge. Cell growth of nongreen potato callus. Approximately $0.1 \mathrm{~g}$ cells were incubated for $30 \mathrm{~d}$ in a solid Murashige and Skoog medium in the presence of different concentrations of the herbicides, as described in the Methods section. Energy charge was calculated as $([$ ATP $]+0.5[A D P]) /([A T P]+[A D P]+$ [AMP]) according to Atkinson (1977). Vertical bars indicate the standard error of the mean (SEM) for five independent experiments. ${ }^{* *} P<0.01 ;{ }^{*} P<0.05$, compared with the control. 
effects on cellular processes. The cellular redox state was strongly decreased by low concentrations of paraquat $(20 \mu \mathrm{M})$; similar results were observed with $50 \mu \mathrm{M}$ 2,4-D (Figure 5). Dicamba decreased cellular redox state by the same level only at concentrations of about $200 \mu \mathrm{M}$.

The gene expression of antioxidant enzymes can be activated and regulated during oxidative stress. Antioxidant enzyme activities are frequently related to mechanisms of herbicides toxicity and resistance (Allen et al., 1997). Therefore, we evaluated the effect of paraquat, 2,4-D and dicamba on the activity of several antioxidant enzymes, namely, SOD, CAT, GR and GST (Figure 6).

CAT activity is stimulated by $1 \mu \mathrm{M}$ paraquat, but significantly inhibited at higher concentrations (Figure 6A). 2,4-D and dicamba increase CAT activity as a function of concentration, with higher efficiency for 2,4-D. The stimulation level induced by $50 \mu \mathrm{M} 2,4-\mathrm{D}$ is $100 \%$ higher than the stimulation induced by dicamba (Figure 6A).

SOD was also affected by the herbicides. SOD activity increased approximately $25 \%$ with dicamba and about 50\% with 2,4-D (Figure 6B). Paraquat, however, was the most efficient, inducing $150 \%$ stimulation.

$\mathrm{GR}$, responsible for the redox cycling of GSH/ GSSG, was stimulated by the three herbicides in a way similar to that observed with SOD (Figure 6C). Using a concentration of $50 \mu \mathrm{M}$, the greatest increase $(\sim 300 \%)$ was promoted by paraquat, followed by $2,4-\mathrm{D}(250 \%)$ and dicamba (180\%).

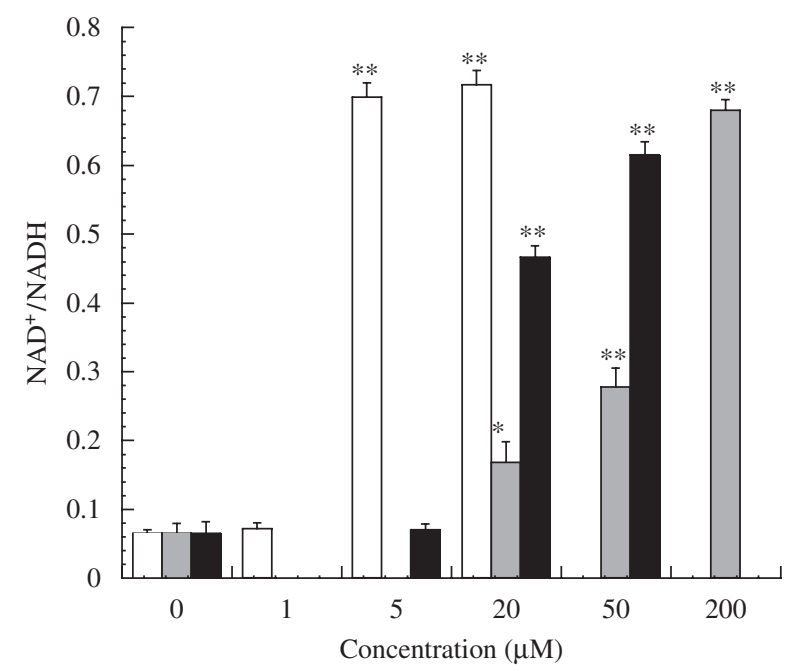

Figure 5. Effects of paraquat (white), dicamba (black) and 2,4-D (gray) on cellular redox state. Cell growth of non-green potato callus. Approximately $0.1 \mathrm{~g}$ cells were incubated for $30 \mathrm{~d}$ in a solid Murashige and Skoog medium in the presence of different concentrations of the herbicides as described in the Methods section. ${ }^{* *} P<0.01$; ${ }^{*} P<0.05$, compared with the control.
GST, in contrast with the other antioxidant enzymes, was not stimulated by paraquat. However, 2,4-D and dicamba also significantly increased this enzyme, with 2,4-D again being the most effective (Figure 6D). At $50 \mu \mathrm{M}$, the activity of GST increased by about $280 \%$ with $2,4-\mathrm{D}$ and $180 \%$ with dicamba.

\section{Discussion}

Examination of callus tissue cultures is an alternative plant model for the evaluation of herbicide toxicity, especially in studies examining herbicide metabolism (Mumma and Davidonis, 1983). With tissue cultures, the barrier to the penetration and translocation of herbicides imposed by the cellular wall is abolished, allowing a more controlled study in the plant metabolic pathways (Magalhães et al., 1989; Nellessen and Fletcher, 1993). Thus, cell cultures have been established and used in ecotoxicological evaluations, and also as a means to study herbicide metabolism in plants (Eding et al., 1984; Harms, 1992).

Paraquat was the most effective on the cell growth, followed by 2,4-D, and then by dicamba. Growth was fully inhibited at concentrations higher than 50,100 and $250 \mu \mathrm{M}$, respectively, for paraquat, 2,4-D and dicamba (Figure 1). The ratio between total protein content and cellular weight (Figure 2) did not correlate with all antioxidant enzymes. However, the data showed a strong correlation with fluorescein release (Figure 3 ). The observed increase in the protein/cell weight ratio, through treatment with 2,4-D and dicamba, was likely the result of a loss of water and electrolytes from the cell rather than an increase of the protein synthesis. This agrees with the observation of an increased number of cells per $g$ of callus, indicating a decrease of cell volume. Consequently, cells become harder and darkbrownish with increasing herbicide concentrations.

From the herbicides under study, only paraquat favored lipid peroxidation (Bus et al., 1974; Kornbrust and Mavis, 1980; Sata et al., 1983). Dicamba and 2,4-D were unable to induce lipid peroxidation resulting from the production of ROS. However, both herbicides have high hydrophobic partition, and can therefore be incorporated into the membrane, affecting its integrity. From the fluorescein release by callus tissue treated with paraquat, 2,4-D and dicamba (Figure 3), we conclude that the cell membrane is severely disrupted by $2,4-\mathrm{D}$, followed by dicamba. Paraquat, 

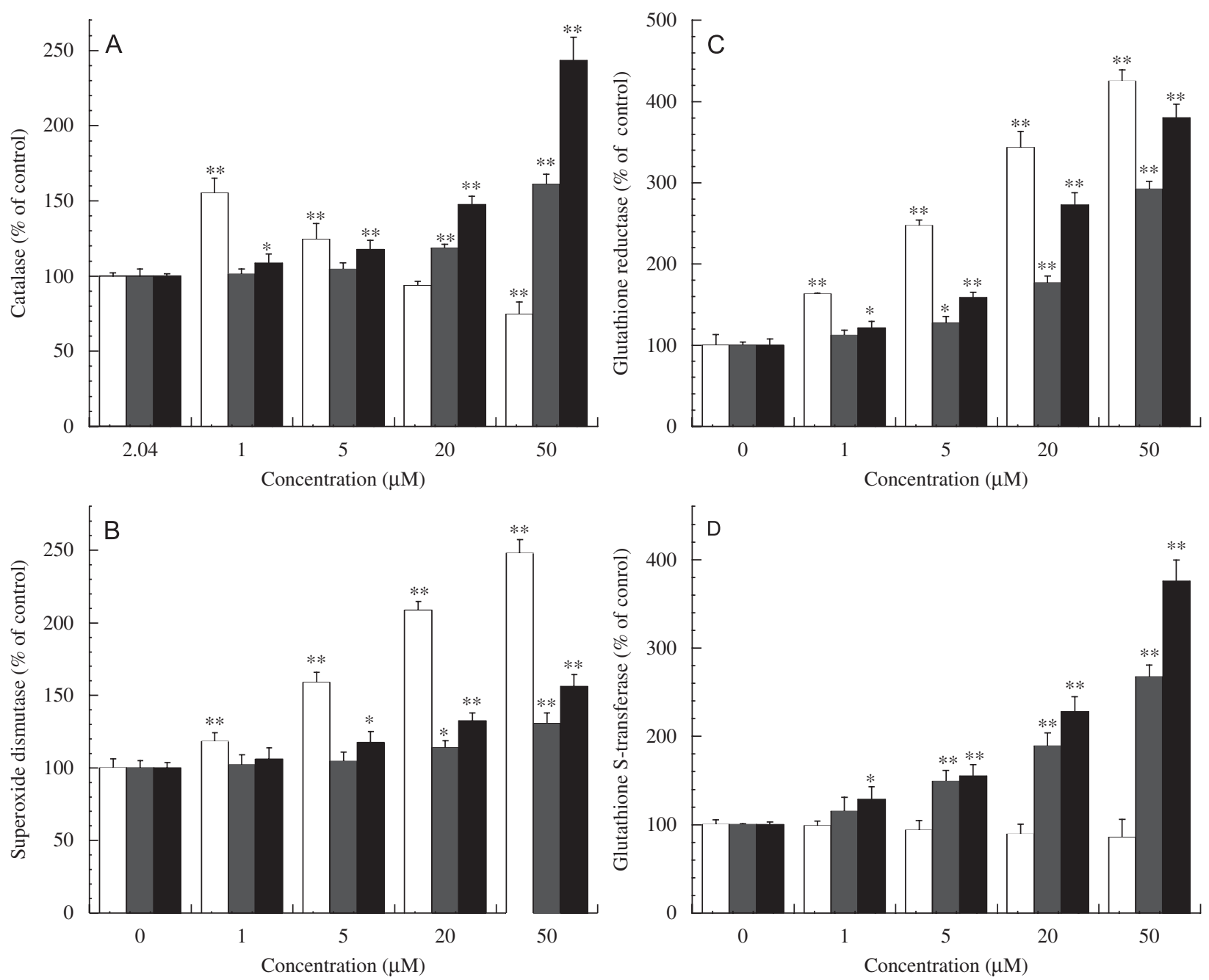

Figure 6. Enzymatic antioxidant activities (catalase (A), superoxide dismutase (B), glutathione reductase (C) and glutathione $S$-transferase (D)) in cell cultures of callus from potato roots exposed to paraquat (white), dicamba (gray) and 2,4-D (black). Approximately $0.1 \mathrm{~g}$ cells were incubated for 30 days in a solid Murashige and Skoog medium in the presence of different concentrations of the herbicides as described in the Methods section. Asterisks indicate significant differences (Student's $t$-test, ${ }^{* *} P<0.01 ;{ }^{*} P<0.05$ ) relative to the control (herbicide absence). Vertical bars indicate the standard error of the mean (SEM) for five independent experiments.

however, did not exert a significant effect on cell membrane integrity under the tested conditions. Thus, toxicity of paraquat was not related to membrane permeability effects, in contrast with 2,4-D, which strongly disturbed membrane integrity.

Because non-green callus tissue was used, the ATP produced in the cell is generated by glycolysis and oxidative phosphorylation. Therefore, herbicide-induced ATP depletion could be related to interference with the mitochondrial or glycolytic energy pathways. The cytotoxic effects of paraquat are believed to be a consequence of reduction of free radical metabolites and subsequent autooxidation with superoxide generation. The reduction undergoes a cyclic process (DeGray et al., 1991).
Therefore, a small amount of paraquat acts as a catalyst for the oxidation of substantial amounts of reduction equivalents, with the concomitant formation of stoichiometric amounts of superoxide (Klimek, 1988). This redox cycling has also been described for quinones and related compounds.

Our earlier studies comparing the effect of paraquat in plant and animal mitochondria have shown that this herbicide strongly decreases the bioenergetic capacity in animal mitochondria, as a result of oxidative stress promoted by paraquat (Vicente et al., 2001). Furthermore, it has also been shown that plant mitochondria are better protected at the antioxidant level, but still susceptible to paraquat toxicity (Vicente et al., 2001; Peixoto et al., 2004). 
All the herbicides tested deplete ATP and ADP with a correspondent increase of AMP (data not shown). Decreased availability of ATP may explain cytotoxicity through reduced ion translocation, nutrient import and metabolite export (Smith and Bryce, 1992). Therefore, the inhibition of growth and death of the cells observed for paraquat, 2,4-D and dicamba were correlated with the cell energy charge decrease (Figure 4). These findings are in agreement with earlier results on nucleotides depletion of cell cultures of hepatocytes exposed to these types of herbicides (Palmeira et al., 1994a). Figure 5 shows that the paraquat effect on the redox state was much more pronounced than the effects of 2,4-D and dicamba, with a stronger effect on the pyridine nucleotides than on adenine nucleotide content. Thus, the cell redox state is preferentially disturbed.

It has previously been demonstrated that some environmental agents can stimulate a plasmatic membrane oxidase (Rasmasarma, 1982), producing $\mathrm{H}_{2} \mathrm{O}_{2}$, which can act as a second messenger and induce a protective response (Foyer et al., 1997; Rasmasarma, 1982). Cell treatment with paraquat induced a significant increase of SOD activity, unlike treatments with 2,4-D and dicamba, which did not induce statistically significant alterations (Figure 6A). These data are in agreement with data showing reactive oxygen species promoted by paraquat, namely superoxide anion (DeGray et al., 1991).

CAT is located primarily in peroxisomes and is responsible for the reduction of hydrogen peroxide produced through the metabolism of long-chain fatty acids in peroxisomes. In callus tissue treated with paraquat, CAT was significantly increased only at lower concentrations $(1-5 \mu \mathrm{M})$.

The inhibition of CAT activity observed at paraquat concentrations higher than $5 \mu \mathrm{M}$ may be attributed to the particularly high sensitivity of this potato CAT to hydrogen peroxide (Beaumont et al., 1990). Furthermore, the increase of SOD activity results in rapid production of hydrogen peroxide, causing its accumulation, since the SOD activity is strongly increased and the SOD turnover is $100 \%$ higher than the CAT turnover (Halliwell and Gutteridge, 1999). These findings are consistent with earlier results in tobacco plants resistant to paraquat, which showed an SOD activity increase, with CAT and peroxidase inhibited (Furusawa et al., 1984).

Treatment with dicamba induced a less pronounced effect on CAT activity compared to 2,4-D $(50 \mu \mathrm{M})$, which strongly stimulated CAT activity with no obvious metabolic meaning. Cellular metabolism and the cell viability would be strongly compro- mised by 2,4-D, perhaps increasing $\mathrm{H}_{2} \mathrm{O}_{2}$ and the consequent CAT activity.

The maintenance of ascorbate and glutathione in the reduced form is very important for efficient protection against ROS. Among the enzymes responsible for the maintenance of these antioxidants on the reduced state, GR has been the best studied. The detoxification of ROS and hydroperoxides requires the oxidation of GSH to GSSG by glutathione peroxidase. GSSG is then reduced to GSH by GR at the expense of NADPH oxidation to $\mathrm{NADP}^{+}$, which is recycled by the pentose phosphate pathway. Nevertheless, if generation of GSSG is higher than the reduction back to GSH by GR, GSSG accumulates and is translocated outside the cell by specific carriers (Kaplowitz et al., 1996; Keppler et al., 1997). GR activity was increased in callus tissue cultures treated with all the tested herbicides (Figure $5 \mathrm{C}$ ). Paraquat promotes GSH oxidation, as has been noted previously by other authors (Burke et al., 1985; Galvani et al., 2000; Palmeira et al., 1994b). Therefore, the GR activity stimulation may occur as a cellular response to an intracellular decrease of GSH.

Glutathione transferase activity was stimulated by dicamba and 2,4-D treatment, but not by paraquat (Figure 6D). GST catalyzes the conjugation of electrophilic herbicides with the tripeptide glutathione, and it has been reported in many plant species (Hatton et al., 1998) as a determinant enzyme for the herbicide detoxification. Our results demonstrate that the GST may be involved in dicamba and 2,4-D detoxification (Hatton et al., 1998), a pattern contrasting with paraquat.

In light of the possible mechanism of paraquat toxicity and the results obtained for GR and glutathione transferase activities, it is clear that the increased activity of these enzymes is exclusively related to the non-enzymatic oxidation of $\mathrm{GSH}$. For dicamba and 2,4-D, the stimulation of GR may also result from an increase of GST, which could drive a decrease in the GSH/GSSG ratio, as GST is involved in detoxifying these herbicides in plant cells.

\section{Acknowledgments}

The authors wish to express their grateful acknowledgment to Dr. Ludovina Lopes, who granted us with potato tuber calli. Francisco Peixoto acknowledges the Chemistry Department of University of Trás-os-Montes and Alto Douro for full support of this study. 


\section{References}

Allen RD, Webb RP, Schake SA. Use of transgenic plants to study antioxidant defenses. Free Radical Biol Med 1997;23:473-9.

Atkinson DE. Cellular energy metabolism and its regulation. New York: Academic Press; 1977.

Beaumont F, Jouve HM, Gagnon J, Gaillard J, Pelmont J. Purification and properties of catalase from potato tubers (Solanum tuberosum). Plant Sci 1990;72:19-26.

Beers RF, Sizer IW. A spectrophotometric method for measuring the breakdown of hydrogen peroxide by catalase. J Biol Chem 1952;195:133-40.

Bradford MM. A rapid and sensitive method for the quantification of microgram quantities of protein utilizing the principle of protein-dye binding. Anal Biochem 1976;72:248-64.

Burke JJ, Gamble PE, Hatfield J, Quisenberry JE. Plant morphological and biochemical responses to field water deficits: I. Responses of glutathione reductase activity and paraquat sensitivity. Plant Physiol 1985;79:415-9.

Bus JS, Aust SD, Gibson JE. Superoxido- and singlet oxygen-catalyzed lipid peroxidation as a possible mechanism for paraquat (Methyl Viologen) toxicity. Biochem Biophys Res Commun 1974;58:749-55.

Carbonera D, Azzone GF. Permeability of inner mitochondrial membrane and oxidative stress. Biochim Biophys Acta 1988;943:245-55.

Cremlyn JR. Agrochemicals. Preparation and mode of action. Chichester, West Sussex, England: Wiley; 1991.

Davies KJA, Delsignore ME, Lin SW. Protein damage and degradation by oxygen radicals II. Modification of amino acids. J Biol Chem 1987;262:9902-7.

DeGray JA, Rao DNR, Mason RP. Reduction of paraquat and related bipyridylium compounds to free radical metabolites by rat hepatocytes. Arch Biochem Biophys 1991;289:145-52.

Eding W, Haque A, Schuphan I, Harms H, Lanbegartels C, Scheel D, et al. Eco-chemical assessment of environmental chemicals: draft guideline of the test procedure to evaluate metabolism and degradation of chemicals by plant cell cultures. Chemosphere 1984; 13:947-57.

Farrington JA, Ebert M, Land EJ, Fletcher K. Bipyridylium quaternary salts and related compounds. V. Pulse radiolysis studies of the reaction of paraquat radical with oxygen. Implications for the mode of action of bipyridyl herbicides. Biochim Biophys Acta 1973;314: 372-81.

Forman HL, Fridovich I. Superoxide dismutase: a comparison of rate constants. Arch Biochem Biophys 1973;158:396-400.

Foyer $\mathrm{CH}$, Delgado HL, Dat JF, Scott IM. Hydrogen peroxide- and glutathione-associated mechanisms of acclimatory stress tolerance and signalling. Physiol Plant 1997;100:241-54.

Furusawa I, Tanaka K, Thanutong P, Mizuguchi A, Yazaki M, Asada K. Paraquat resistant tobacco calluses with enhanced superoxide dismutase activity. Plant Cell Physiol 1984;25:1247-54.
Galvani P, Cassani A, Fumagalli P, Santagostino A. Effect of paraquat on glutathione activity in Japanese Quail. Bull Environ Contam Toxicol 2000;64:74-80.

Habig WH, Pabst MJ, Jakoby WB. Glutathione S-transferases: the first enzymatic step in mercapturic acid formation. J Biol Chem 1974;249:7130-9.

Halliwell B, Gutteridge JMC. Antioxidante defences. Free radicals in biology and medicine. London: Oxford University Press Inc.; 1999. p. 105-244.

Harms H. In-vitro systems for studying phytotoxicity and metabolic fate of pesticides and herbicides in plants. Pestic Sci 1992;35:277-81.

Hatton PJ, Cummins I, Price LJ, Cole DJ, Edwards R. Glutathione transferases and herbicide detoxification in suspension-cultured cells of Giant foxtail (Setaria faberi). Pestic Sci 1998;53:209-16.

Kaplowitz N, Fernandez-Checa JC, Kannan R, Garcia-Ruiz C, Ookhtens M, Yi JR. GSH transporters: molecular characterization and role in GSH homeostasis. Biol Chem 1996;377:267-73.

Keppler D, Leier I, Jedlitschky G. Transport of glutathione conjugates and glucuronides by the multidrug resistance proteins MRP1 and MRP2. Biol Chem 1997;378: 787-91.

Klimek J. The involvement of superoxide and iron in the nadph-dependent lipid peroxidation in human placental mitochondria. Biochim Biophys Acta 1988;958: 31-9.

Kornbrust DJ, Mavis RD. The effect of paraquat on microsomal lipid peroxidation in vitro and in vivo. Toxicol Appl Pharmacol 1980;53:323-32.

Lambert CE, Bondy SC. Effects of MPTP, MPP ${ }^{+}$and paraquat on mitochondrial potential and oxidative stress. Life Sci 1989;44:1277-84.

Magalhães MJA, Ferreira JR, Frutuoso L, Taínha A. Study of the disappearance of endosulfan, parathion, trichlorfon and pirimicard from broccoli and Portuguese cabbage. Pestic Sci 1989;27:23-31.

Mishra A, Choudhuri MA. Effects of salicylic acid on heavy metal-induced membrane deterioration mediated by lipoxygenase in rice. Biol Plant 1999;42: 409-15.

Montezuma CJ, Guimarães ML. Isolation of callus from potato roots. Bol Soc Brot Ser 1976;2:265-71.

Mumma RO, Davidonis GH. Progress in pesticide biochemistry and toxicology. In: Hutson $\mathrm{DH}$, Roberts R, editors. Plant tissue culture and pesticide metabolism. Chichester: Wiley; 1983. p. 255-74.

Nellessen JE, Fletcher JS. Assessment of published literature pertaining to the uptake/accumulation, translocation, adhesion and biotransformation of organic chemicals by vascular plants. Environ Toxicol Chem 1993;12:2045-52.

Nordquist RE, Nguyen H, Poyer JL, Carubelli R. The role of free radicals in paraquat-induced corneal lesions. Free Radical Res 1994;23:61-71.

Palmeira CM, Moreno AJ, Madeira VMC. Metabolic alterations in hepatocytes promoted by the herbicides paraquat, dinoseb and 2,4-D. Arch Toxicol 1994a;68: 24-31. 
Palmeira CM, Moreno AJ, Madeira VMC. Interactions of herbicides dinoseb and 2,4-D with liver mitochondrial bioenergetics. Toxicol Appl Pharmacol 1994b;127: 50-7.

Pamplona R, Portero-Otín M, Requena JR, Thorpe SR, Herrero A, Barja G. A low degree of fatty acid unsaturation leads to lower lipid peroxidation and lipoxidation-derived protein modification in heart mitochondria of the longevous pigeon than in the short-lived rat. Mech Ageing Dev 1999;106(3): 283-96.

Peixoto F, Vicente J, Madeira VMC. A comparative study of plant and animal mitochondria exposed to paraquat reveals that hydrogen peroxide is not related to the observed toxicity. Toxicol Vitro 2004; 18:733-9.

Persidsky MP, Baillie CS. Fluorometric test of cell membrane integrity. Cryobiology 1977;14:322-5.

Rasmasarma T. Generation of $\mathrm{H}_{2} \mathrm{O}_{2}$ in biomembranes. Biochim Biophys Acta 1982;694:279-84.

Sandermann H, Scheel D, Trenck TVD. Use of plant cell cultures to study the metabolism of environmental chemicals. Ecotoxicol Environ Saf 1984;8:167-82.

Sata T, Takeshige K, Takayanagi R, Minakami S. Lipid peroxidation by bovine heart submitochondrial particles stimulated by $1,1^{\prime}$-dimethyl-4,4'-bipyridylium dichloride (paraquat). Biochem Pharmacol 1983;32: 13-9.

Scandalios JG. Oxygen stress and superoxide dismutases. Plant Physiol 1993;101:7-12.

Schaedle M. Chloroplast glutathione reductase. Plant Physiol 1977;59:1011-2.

Sies H. Strategies of antioxidant defense. Eur J Biochem 1993;215:213-9.

Smeda RJ, Weller SC. Plant-cell and tissue-culture techniques for weed science research. Weed Sci 1991; 39:497-504.

Smith JAC, Bryce JH. Metabolite compartmentation and transport in CAM plants. In: Tobin AK, editor. Plant organelles. Compartmentation of metabolism in photosynthetic tissue. London: Cambridge University Press; 1992. p. 141-67.

Stocchi V, Cucchiarini L, Magnami M, Chiarantini L, Palma P, Crescentini G. Simultaneous extraction and reversephase high-performance liquid chromatographic determination of adenine and pyridine nucleotides in human red blood cells. Anal Biochem 1985;146: 118-24.

Vicente JAF, Peixoto F, Lopes ML, Madeira VMC. Differential sensitivities of plant and animal mitochondria to the herbicide paraquat. J Biochem Mol Toxicol 2001;15(6):322-30. 